\title{
Téoros
}

Revue de recherche en tourisme

\section{La prochaine étape est enclanchée} L'appui du gouvernement canadien à l'industrie des congrès

\section{Guy Bédard}

Volume 4, numéro 3, novembre 1985

L'essor de l'industrie des congrès

URI : https://id.erudit.org/iderudit/1080792ar

DOI : https://doi.org/10.7202/1080792ar

Aller au sommaire du numéro

Éditeur(s)

Université du Québec à Montréal

ISSN

0712-8657 (imprimé)

1923-2705 (numérique)

Découvrir la revue

Citer cet article

Bédard, G. (1985). La prochaine étape est enclanchée : l'appui du gouvernement canadien à l'industrie des congrès. Téoros, 4(3), 29-29.

https://doi.org/10.7202/1080792ar d'utilisation que vous pouvez consulter en ligne.

https://apropos.erudit.org/fr/usagers/politique-dutilisation/ 


\title{
L'appui du gouvernement canadien à l'industrie des congrès
}

\section{La prochaine étape est enclanchée}

\author{
par Guy Bédard*
}

La présente décennie aura marqué de façon définitive l'entrée du Canada dans les "ligues majeures" de l'industrie mondiale du congrès. Depuis Montréal en 1983, en passant par Toronto en 1984, jusqu'à Vancouver au début de 1987, le Canada aura plus que doublé sa capacité d'accueil de congrès de grande envergure et de foires commerciales. Les principaux centres de congrès qui ont vu le jour ou ont réalisé des projets d'expansion au cours de la période 1977-87 totalisent des investissements privés et publics de plus de 460 millions $\$$.

Le marché international des conférences et des congrès représente un chiffre d'affaires de l'ordre de 60 milliards \$. De ce nombre, 25 milliards $\$$ proviennent des Etats-Unis. Le Canada retire environ 1 milliard $\$$ de revenus de ce marché total, dont 700 millions \$ originent du marché américain. Selon le système d'impact touristique, il est possible d'estimer que chaque tranche de 23000 \$a 28000 \$, sous forme de revenus additionnels, contribue à la création d'un emploi au Canada. Un accroissement modeste de notre part de ce marché ajouterait ainsi plusieurs dizaines de millions de dollars aux recettes touristiques. du Canada et aurait un impact significatif sur le plan de l'emploí.

C'est dans cette optique que des investissements importants ont été réalisés dans les infrastructures de congrès des principales villes canadiennes. Cependant, nous ne faisons pas cavalier seul dans la recherche d'une plus grande part de marché. La plupart des pays industrialisés possèdent une infrastructure de calibre international et la croissance de la demande demeure modeste, soit de 3 à $5 \%$ annuellement. Par conséquent, les associations et les corporations qui organisent des congrès, des voyages de motivation et des réunions d'affaires sont sollicitées de toutes parts, ce qui contribue à rendre ce marché de plus en plus sophistiqué.

\footnotetext{
"Guy Budard est directeur du Tourisme pour la région du Québec iministère de l'Expansion industrielle régionale-gouvernement du Canadal.
}

L'étude Metropoll I et II réalisée par la firme Survey Research Associates, qui fait l'objet d'une analyse dans le présent cahier, fait ressortir le positionnement modeste des principales villes canadiennes (Toronto (25). Montréal (39), Vancouver (39) I par rapport à 75 villes du marché nordaméricain, en terme d'intention de tenir un congrès durant les trois prochaines années. L'étude fait ressortir également le grand nombre et la diversité de facteurs qui influencent le choix d'une destination de congrès.

Après avoir largement contribué financièrement à l'implantation de ces nouvelles installations, les gouvernements doiventils laisser aux règles normales du marché la rentabilisation économique de ces équipements? Si non, quel rôle les autorités gouvemementales, et en particulier le gouvernement du Canada, doivent-elles jouer?

II appartient à ceux qui sont sur la ligne de feu et qui doivent "booker" leurs installations de congrès d'être les acteurs du développement de l'industrie canadienne des congres. Cependant, les enjeux sont importants et le Canada se doit d'être compétitif au plan intemational. Dans ce contexte, le gouvernement du Canada pourrait fournir un appui à l'industrie, principalement sur deux plans:

Dans un premier temps, son intervention pourrait se situer au plan de la création d'un climat général propice au développement de l'industrie du congrès. Son action pou= rait se traduire ainsi:

- un rôle de leadership au plan de la recherche, de l'analyse et des études, de façon à développer un "market intelligence $^{r}$ accessible aux intervenants touristiques du secteur;

- la mise en place de mesures fiscales jugées essentielles ou de toute politique horizontale qui permettrait, soit de lever des contraintes, soit de stimuler le développement de l'industrie (fiscalité, transport, douanel:

- un positionnement général de I'offre canadienne sur les principaux marchés, i.e. une stratégie de notoriété visant à intégrer les destinations canadiennes de congrès dans les circuits de congrès.

Dans un second temps, son intervention pourrait se faire au niveau d'un appui financier direct auprès des intervenants. Toutefois, son intervention doit être guidée par un certain nombre de principes directeurs qui lui permettront d'obtenir le meilleur rendement possible de son investissement. Ainsi, la priorité doit être accordée à des interventions axées sur l'accroissement de la compétitivité de l'offre canadienne au plan international, sur l'augmentation de la part du Canada des marchés de congrès internationaux et sur la recherche de bénéfices économiques nets importants pour le Canada.

Cette intervention se doit d'être harmonisée et coordonnée avec les autres intervenants. A cet effet, la formule des ententes fédérales-provinciales apparaît être un véhicule approprié. Jusqu'à maintenant, des ententes ont été signées avec tous les gouvernements provinciaux et ceux des territoires. Elles représentent quelques 400 millions \$ $d^{\prime}$ investissements additionnels des gouvernements dans le secteur touristique au cours des cinq prochaines années.

Au Québec, l'entente a reconnu comme prioritaire le secteur des congrès internationaux. L'intervention conjointe se situera à l'intérieur des principes énoncés précédemment. Elle privilégiera donc les destinations de Montréal et Québec, et les congrès à participation majoritairement internationale. Son champ d'action se veut complémentaire à celui des autres intervenants et se situera donc plus particulièrement auprès des associations ou des organismes de façon à les appuyer au moment de la sollicitation, de l'organisation et de la tenue d'un congrès international.

"La prochaine étape" est déjà enclenchée, mais il reste encore beaucoup à faire. 